\title{
An Immunochemical Approach to Model and Long-Term Suppression of Depressive and Anxiety Behavior
}

\author{
Igor P. Ashmarin, Raisa A. Danilova, Olga I. Rud'ko, Maria V. Belopolskaya, \\ Maria F. Obukhova, and Elena V. Shmalgausen \\ Moscow State University
}

\begin{abstract}
The inhibitor of monoaminooxydase isatin and the ligand of B-receptors cholecystokinin4 play a significant role in the suppression and induction of depressive and anxiety states. We induced the formation of auto-antibodies to these compounds against their conjugates with antigen-carrier by immunization of white rats. The result was long-term (more than 2 months) stimulation of depressive and anxiety behavior after immunization to isatin and, in contrast, the suppression of such behavior after immunization to cholecystokinin. The perspective of immunochemical approach to long-term correction of behavior is discussed. Keywords: Depression, modeling, immuno-correction, active immunization, cholecystokinin4, isatin, biogenic amines, rats.
\end{abstract}

El inhibidor de la monoaminooxidasa isatin y el ligando de B-receptores colecistokinina4 juegan un papel significativo en la supresión e inducción de los estados de ansiedad y depresión. Nosotros hemos inducido la formación de auto-anticuerpos contra estas sustancias mediante la inmunización de ratas blancas. El resultado fue la estimulación prolongada (más de 2 meses) de conducta depresiva y de ansiedad tras la inmunización con isatin y, por el contrario, la supresión de esta conducta después de la inmunización con colecistokinina. En el artículo se discute la posibilidad de la corrección de la conducta a largo plazo mediante la manipulación immunoquímica.

Palabras clave: Depresión, remodelación, immuno-corrección, inmunización activa, colecistokinina-4, isatin, aminas biogénicas, ratas.

Correspondence concerning this article should be addressed to: Igor P. Ashmarin, Dept. of Human Physiology, School of Biology, Moscow State University, Vorobiovy Gory, Moscow, 119922, Russia. FAX: (095) 93933 55. E-mail: ashmarin25@mail.ru 
For the comprehension of the pathogenesis of depression and the search for effective antidepressants, it is important to acquire the most adequate experimental model of protracted depression. Existing models, based on pharmacological action, as well as on electrolytic, surgical, or ischemic damage to specific brain regions and so on have one significant shortcoming in the form of their brief duration. Over the past years, several hypotheses and data relating to the role of neuroimmunological processes in the pathogenesis of depression have been presented (Leonard, 2001; Friedman, Becker, Overstreet, \& Lawrence, 2002; Arushanyan \& Bayer, 2004). The search for new and more effective modeling for and suppression of depression has led us to refer to the method of inverse immunoregulation (Ashmarin, Danilova, \& Obukhova, 2001; Ashmarin \& Gomazkov, 1992; Danilova, \& Ashmarin, 1994) consisting of the induction of the formation of auto-antibodies to endogenous chemical regulators. If the regulator in question is a low-molecular compound, immunogenicity is attained by covalent conjugations with a neutral antigen carrier. The duration of such induced formation of auto-antibodies in primary immunization is $3-8$ months, and in secondary immunization - years.

Important factors limiting the activity of mono-oxidases and the development of depression are the endogenous regulators isatin and tribuline (Medvedev \& Glover, 2004). Exogenous analogues of these compounds are antidepressants such as pargyline, deprenyl, and so on.

Previously, we were able to establish the possibility of artificially creating protracted depressive states in experimental animals by the induction of auto-antibodies to the psycho-stimulant with antidepressive effects sydnophen, as well as to exogenous inhibitors of monoamine oxidase (MAO), antidepressants, pargyline, and deprenyl (Ashmarin, Danilova, Mashkovskii, et al., 1990; Ashmarin, Danilova, Mel'nik, et al. 1989; Danilova, Belopolskaya, Kushnir, Moskvitina, et al., 2000; Danilova, Obukhova, Ashmarin, et al., 1988; Danilova, Obukhova, Belopolskaya, \& Ashmarin, 1998; Danilova, Moskvitina, Obukhova, Belopolskaya, \& Ashmarin, 1999).

Immunization was accompanied by the formation of antibodies to pargyline or deprenyl, increased activity of MAO, and changes in the concentration of biogenic amines. These biochemical changes correlated with severe and protracted behavioral changes in rats, indicating the presence of depression (decreased exploratory activity, increased immobilization period in the Porsolt test, as well as signs of anxiety).

In the present study, immunization of rats was attained using covalent conjugates of the endogenous MAO inhibitor isatin with an antigen carrier, with consecutive immunologic and biochemical assays and behavioral analysis.

The effectiveness of the immunochemical approach to the modeling of depressive states and their duration allows for the affirmative evaluation of the perspectives of the present course and the possibility of long-term correction of pathologicalal states of anxiety and depression. Despite the availability of a wide range of anxiolytics and antidepressants, the problem of the correction of pathological anxiety and depression is far from successful solution. Such a possibility may have come about following the discovery of endogenous anxiety factors, the most effective of which is the tetrapeptide Trp-Met-Asp-Phe- $\mathrm{NH}_{2}$ - cholecystokinine4 (CCK-4). As revealed, an anxiogenic effect is noted not only in CCK-4 itself, but also in its structural analog, CCK3 (Met-Asp-Phe- $\mathrm{NH}_{2}$ ). This fact has served as the basis for the study of immunological correction of states of anxiety and phobia based on the immunization of white rats with conjugates of CCK-4 and CCK-3 with antigen carriers (Ashmarin, Danilova, Rud'ko, Obukhova, \& Andreeva, 2004; Danilova, \& Fedorova, 2001; Danilova, Rud'ko, O.I., Korotkova, Obukhova, \& Ashmarin, 2002).

\section{Material and Methods}

\section{Subjects}

The present study was carried out on white male Wistar rats weighing 150-180 $\mathrm{g}$ at study commencement. The animals were placed in a vivarium with controlled SPF conditions: air temperature $22 \pm 2^{\circ} \mathrm{C}$, relative humidity $50 \pm 5 \%$, automatic time-period changes with "daytime" from 8:00 to 20:00 and "night" from 20:00 to 8:00. The rats were kept in plastic cages $(60 \times 35 \times 20 \mathrm{~cm})$, equipped with steel latticed lids, feeding niches, and separators with wood filings as litter for 7-8 rats per cage (no more). Extruded and balanced mixed fodder PK-120-1 for laboratory rats and mice (OOO “LABORATORSNAB” GOST P 50258-92) was provided ad libitum. Water was provided in standard water bottles with steel nozzles.

Each series of experiments included no less than 10-12 control and study rats. Each series was repeated 2-3 times.

\section{Procedure}

Immunization of rats. Immunization of rats was attained using the MAO inhibitors isatin and deprenyl (N-dimetyl$\mathrm{N}$ [2-propyl] benzenethanamine hydrochloride, ICN Biomedical Inc., USA), and fragments 30-33 (Trp-Met-AspPhe- $\mathrm{NH}_{2}$ ) and 31-33 (Met-Asp-Phe- $\mathrm{NH}_{2}$, ICN Biomedical Inc., USA) of cholecystokinine covalently conjugated the antigen carrier bovine serum albumin (BSA). The synthesis of conjugates was carried out using the binding agent carbodiimide -1 (N-ethyl-N'3-dimethylaminopropyl muriatic carbodiimide) in molar ratio 1:100. The immunization of the rats with the conjugates was carried out three times subcutaneously at four points of the back with an interval of 7-8 days; the first two times using Freund's adjuvant immunostimulant (ICN Biomedical Inc., USA) in volume ratio $1: 1$. Immunization dosage was chosen by calculation 
using 600-800 $\mu \mathrm{g}$ per kilogram mass. The controls were administered adjuvant with physiological saline solution.

Immunological Assessments. Immunological assessments of blood serum of the control and study rats were carried out using ELISA technique; phosphate buffer pH 7.5.

Biochemical Assessments. For the assessment of MAO activity, mitochondria of the experimental animals were extracted from their livers and brains by differential centrifuge in a $0.25 \mathrm{M}$ sucrose solution. MAO activity was measured according to the accumulation of tainted product $(450 \mathrm{~nm})$ in the oxidation of p-nitrophenylethylamine at $25^{\circ} \mathrm{C}$. The reaction composite consisted of $950 \mu$ of $50 \mathrm{mM}$ phosphate buffer, $\mathrm{pH} 7.4,25 \mathrm{mg}$ tritone $\mathrm{X}-100,50 \mu \mathrm{l}$ mitochondria suspension and $0.1 \mathrm{mM}$ p-nitrophenylethylamine. Alteration of the absorption at 0.01 corresponded to 0.33 nmole NH4+.

The concentration of monoamines and their metabolites in the striatum was assessed using the method of highperformance liquid chromatography with electrochemical detection.

Behavioral Testing. Behavioral testing was carried out 3-4 weeks following immunization and later (after 2-2.5 months) with the following tests.

1. Rat motor and orientation-exploratory activity with the registration of horizontal and vertical components was assessed using the automatic apparatus "RODEO." This apparatus is a darkened chamber (50 $\times 50 \times 20 \mathrm{~cm}$ ) with 16 apertures (diameter $3.5 \mathrm{~cm}$ ) at its base and 25 on its lid. With the aid of light sensors in the chamber, automatic registration of the parameters of horizontal activity (in conditional units), the quantity of vertical stance, and the quantity of explored upper and lower burrows was conducted. The total test period was either 5 or 10 minutes.

2. Anxiety components and fear in the rats' behavior was assessed using an elevated cross maze. The maze was made up of a cross platform elevated above the floor on a central mount at a height of $80 \mathrm{~cm}$ with four perpendicular beams $10 \mathrm{~cm}$ wide and $45 \mathrm{~cm}$ long, at the intersection of which there is a central open platform $10 \times 10 \mathrm{~cm}$. One pair of opposite beams has 3 opaque flanks and the other pair of beams is transparent. The rats were placed at the center of the maze facing the transparent beam. Visual registration of indices such as exits to the open beams, the time spent in them, total number of transitions, risk behavior, quantity of stances, freezing time, latent period before motion commencement, first entry to the dark chamber, and the amount of defecations were carried out during a period of 5 minutes.

3. For the identification of anxiety components, the "light/dark" test was used. The animals were placed in a box divided into two compartments by an opaque partition (dimensions, $20 \times 20 \mathrm{~cm}$ ). One compartment was illuminated, the other dark. The rats were able to move freely between compartments. The rats were placed in the illuminated compartment and the latent period of movement to the dark compartment was registered. Further, the quantity of transitions from the illuminated compartment to the dark compartment and the total time in the illuminated compartment was assessed. The total testing time comprised 5 minutes.

4. The disposition of the rats to the development of depression-like states was assessed using Porsolt's method in the test of unavoidable swimming. The rats were placed in a semitransparent plastic tank $45 \mathrm{~cm}$ high filled up to $30 \mathrm{~cm}$ with water of $20-21^{\circ} \mathrm{C}$. Using a computer program, the duration of protracted active (vigorous movements in all extremities) and passive (feeble paddling in the hind paws) swimming and immobility was registered for 10 minutes.

\section{Statistical Analysis}

Statistical analysis of the acquired data was carried out using Wilcoxon-Mann-Whitney U-criteria and statistical computer software Excel and Statistica.

\section{Results}

\section{Results of Isatin BSA Conjugate Immunization}

Immunological effects. Immunization with isatin BSA conjugate led to the formation of a significant and persistent concentration of antibodies to isatin with mean titer 1:12800 (control titer, 1:160). As shown in Table 1, the antibody titer in immunization to isatin is higher than immunization to the exogenous regulator deprenyl. The difference in titer in the control and study groups was statistically significant $(p<.001)$.

Table 1

Inmunological Assessment Indexes

\begin{tabular}{lrr}
\hline \multirow{2}{*}{ Groups } & \multicolumn{2}{c}{ Antibody Titer } \\
\cline { 2 - 3 } & \multicolumn{1}{c}{ Deprenyl } & Isatin \\
\hline Controls: $n=40$ & $1: 160$ & $1: 160$ \\
Deprenyl Immunization Group: $n=25$ & $1: 6400$ & $1: 6400$ \\
Isatin Immunization Group: $n=25$ & $1: 12800$ & $1: 12800$ \\
\hline
\end{tabular}


Table 2

MAO Activity (Nmole Nh4+/Min) after Immunization with Deprenyl and Isatin Conjugates

\begin{tabular}{lcc}
\hline Groups & Liver & Brain \\
\hline Controls: $n=10$ & $0.166+0.015$ & $0.1+0.02$ \\
Deprenyl: $n=10$ & $0.192 \pm 0.007(116 \%)$ & $0.153 \pm 0.011(153 \%)^{*}$ \\
Isatin: $n=10$ & $0.145 \pm 0.009(87.3 \%)$ & $0.186 \pm 0.02(186 \%)^{* *}$ \\
\hline
\end{tabular}

$* p<.05 . * * p<.01$.

The results of cross reaction provide evidence of the fact that all deprenyl antibodies were significantly reactive to isatin and vice versa, all isatin antibodies reacted with deprenyl.

Biochemical effects. Data represented in Table 2 show the statistically significant increase in MAO activity in the immunized rats' brains and, furthermore, this increase in rats immunized with isatin was more pronounced than in rats immunized with deprenyl.

A consequence of the alteration in MAO activity is the statistically significant decrease in serotonin and the concentration of its metabolites in the brain striatum. Furthermore, dopamine concentration remained at the same concentration as in controls, although the concentration of its metabolites increased (see Figure 1).

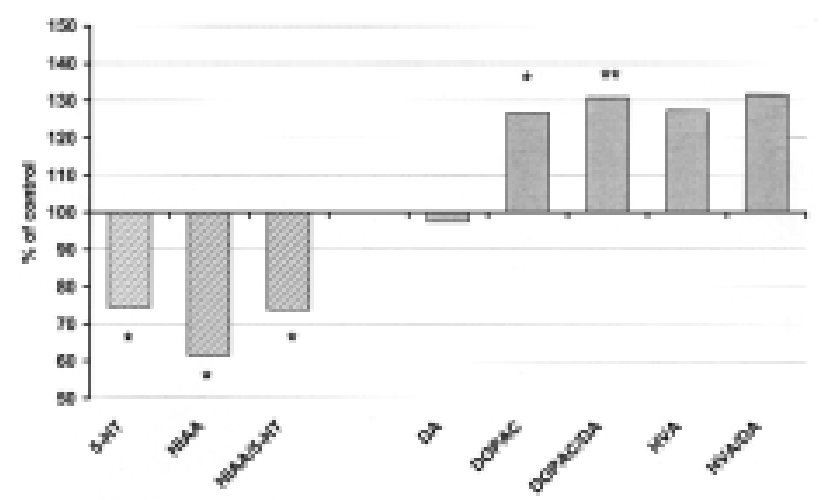

Figure 1. Biochemical changes in rat brain striatum following immunization with isatin BSA conjugate (\% of control).

Controls: $n=12$; study group: $n=12$

Statistical significance (Wilcoxon-Mann-Whitney $U$-criteria): $* p$ $<.05 .{ }^{* *} p<.01$.

Table 3

Unavoidable Swimming Test Indexes in Rats Immunized with Isatin Conjugate

\begin{tabular}{lccc}
\hline Groups & Active swimming & Passive swimming & Immobility \\
\hline Controls: $n=20$ & $142.9 \pm 15.3 \mathrm{~s}$ & $379.6 \pm 26.5 \mathrm{~s}$ & $77.6 \pm 9.3 \mathrm{~s}$ \\
Isatin: $n=20$ & $77.32 \pm 9.8 \mathrm{~s}^{* * *}$ & $330.4 \pm 23.4 \mathrm{~s}$ & $192.5 \pm 14.6 \mathrm{~s} * * *$ \\
\hline
\end{tabular}

Behavioral effects of immunization. The results of the unavoidable swimming test used for the assessment of depressive components in animal behavior are presented in Table 3.

As is evident, rats immunized with isatin conjugates revealed a significant decrease in active swimming time ( $p$ $<.001)$ in comparison to controls and, most importantly, there was a significant increase in time of immobility $(p<$ .001). Results of the unavoidable swimming test carried out twice (the first 3-4 weeks after immunization and at later stages, 2-2.5 months after immunization) in one series with rats immunized with a conjugate of endogenous MAO inhibitor isatin and exogenous inhibitor deprenyl showed the development of more severe depression of behavioral activity following immunization with isatin (see Figure 2).

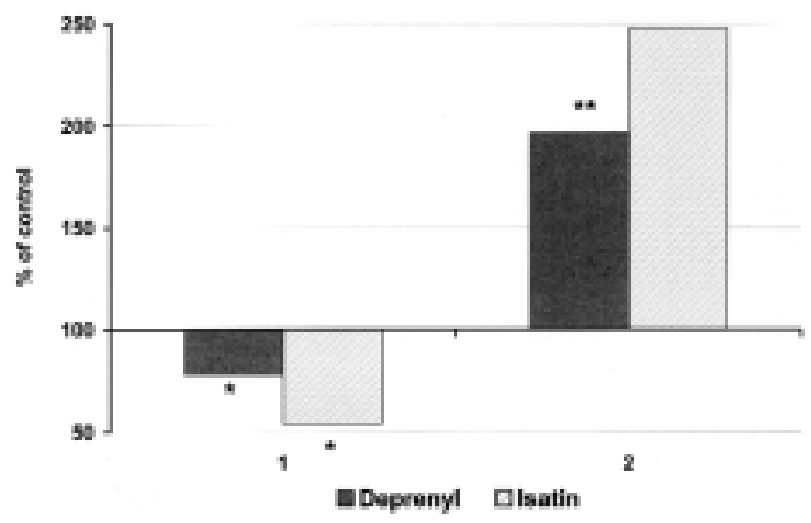

Figure 2. Indices of unavoidable swimming following immunization of rats with deprenyl and isatin conjugates (\% of control): $1=$ time of active swimming; $2=$ immobility period. Controls: $n=20$; deprenyl immunization: $n=20$; Isatin immunization: $n=20$. Statistical significance (Wilcoxon-Mann-Whitney $U$-criteria): ${ }^{*} p$ $<.05 . * * p<.01$.

$* * * p<.001$. 
Testing the rats in the cruciform maze showed a decrease in the amount of total transitions, a significant increase in latent period of motion initiation $(231 \%$ of controls, $p<$ $.05)$ and immobility period (147.4\% of controls, $p<.05)$, which may indicate a decrease in orientation-exploratory activity in the maze. It is important that in the automated open field, no decrease in motor activity was noted. Furthermore, immunized rats in the maze showed changes in indices of anxiety and fear components, that is, a decrease in exits to open beams and time spent in them (40 and 16.9\% accordingly of controls), and an increase in the amount of defecation. During the period spent within the cruciform maze, some rats showed pronounced anxiety and fear reactions such as agitation, turning, moving backwards.

The use of the antidepressant fluoxetine for the alleviation of depressive components showed that acute administration of fluoxetine to rats immunized with deprenyl and isatin (20 $\mathrm{mg} / \mathrm{kg}$ thrice daily) led to the increase in active swimming time practically to the level of controls (see Figure 3). However, immobility period remained unchanged. Chronic administration of fluoxetine (during 1 week) not only increased the period of active swimming but also decreased the time of immobility, although these changes did not reach significance. The partial alleviation of depressive symptoms with fluoxetine in rats in particular, demonstrated the extent and stability of the depressive effect of immunization with MAO inhibitors.

\section{Results of Rat Immunization with Cholecystokinine-4 BSA Conjugate}

Behavioral effects. As opposed to immunization with MAO inhibitors, immunization to the anxiety factor CCK4 and its structural analogue CCK-3 led to the completely opposite effects. In the test of unavoidable swimming in immunized rats, the indices were directly opposite: The time of active swimming increased in comparison to controls and the time of immobility significantly decreased (see Table 4).

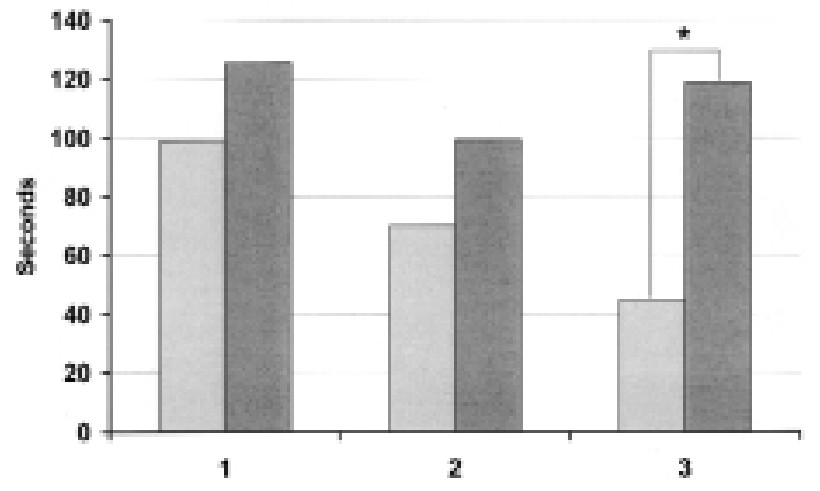

Figure 3. The influence of fluoxetine on the indices of active swimming in control rats (1), isatin conjugate immunized rats (2), and deprenyl conjugate immunized rats (3). Light bars $=$ indices of the groups prior to administration; dark bars = following fluoxetine administration.

Number of rats in each group: $n=10$

Statistical significance (Wilcoxon-Mann-Whitney $U$-criteria: $* p<.05$.

Testing in the cruciform maze also showed several behavioral changes, bearing evidence not only of the absence of anxiety and fear components noted in rats immunized with MAO inhibitors, but also of a decrease in anxiety of the immunized animals in comparison to controls (see Figure 4). There was an increase in the number of exits to the open sectors and time spent within them, risk behavior, and exploratory activity, and a decrease in the time of freezing in comparison to controls. Behavioral changes in immunized rats in the automated open field showed a stimulatory effect of immunization on motor and orientation-exploratory activity. As of the $5^{\text {th }}$ minute, when the activity of control rats decreased, the immunized animals showed a high level of motor and orientation-exploratory activity (see Figure 5). Using the "light/dark" test, we observed an increase in the amount of exits of the immunized rats to the illuminated compartment and the time spent in it in comparison with controls (see Table 5), which also reveals the anxiolytic effect of immunization.

Table 4

Unavoidable Swimming Test Indexes Following Immunization with CCK-4 BSA Conjugate

\begin{tabular}{llrr}
\hline Groups & Active swimming & Passive swimming & Immobility \\
\hline Controls: $n=20$ & $121.80 \pm 19.52 \mathrm{~s}$ & $313.29 \pm 25.34 \mathrm{~s}$ & $170.36 \pm 24.75 \mathrm{~s}$ \\
CCK-4: $n=20$ & $183.45 \pm 17.23 \mathrm{~s}^{*}$ & $350.35 \pm 27.32 \mathrm{~s}$ & $56.20 \pm 10.26 \mathrm{~s} * * *$ \\
\hline
\end{tabular}

$* p<.05 . * * * p<.001$.

Table 5

Behavior Indices of Rats Immunized with CCK-3 and CCK-4 in the "Light/Dark" Test

\begin{tabular}{lcc}
\hline Groups & Number of Exits to Illuminated Compartment & Time Spent in Illuminated Compartment (in seconds) \\
\hline Controls & $2.00 \pm 0.51$ & $24.10 \pm 6.56$ \\
Immunized with CCK-3 & $3.63 \pm 1.04 *$ & $41.25 \pm 14.52 *$ \\
Immunized with CCK-4 & $3.60 \pm 1.10^{* *}$ & $33.10 \pm 12.20$ \\
\hline
\end{tabular}

${ }^{*} p<.05 .{ }^{*} p<<.01 .{ }^{*} p<.05 .{ }^{*} p<<.01$. 

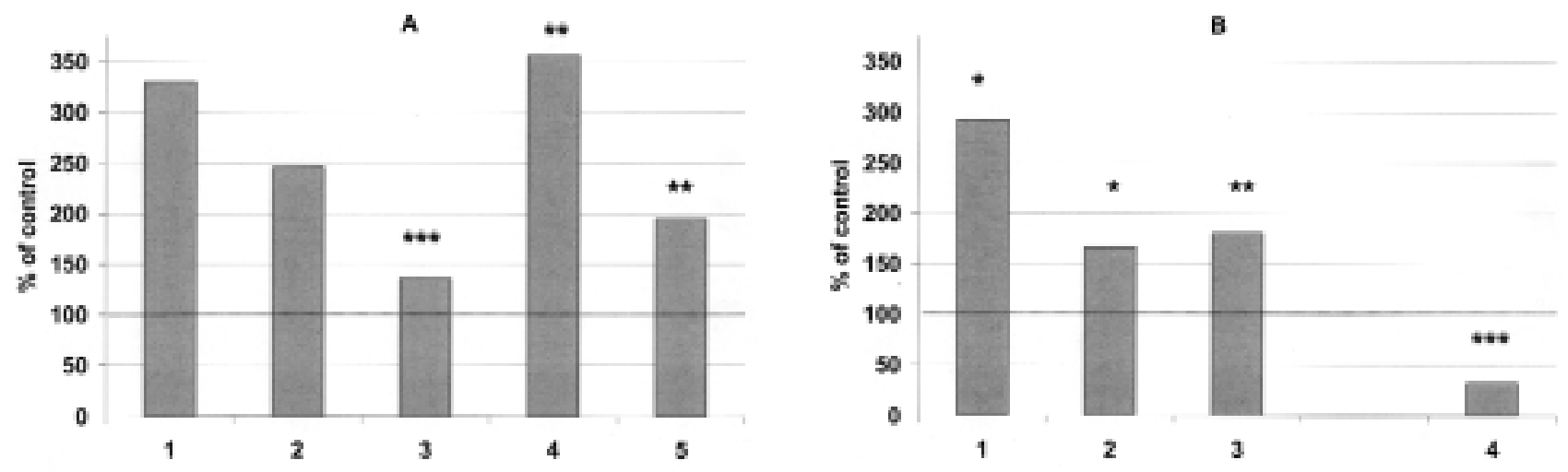

Figure 4. Behavior of rats immunized with CCK-4 conjugate in the "plus" maze (\% of control).

A. Indices characterizing anxiolytic effect: $1=$ number of exits to open beams; $2=$ time in open beams; $3=$ ratio open/closed exits; $4=$ time in closed beams; 5 = risk behavior.

B. Indices of orientation-exploratory activity: $1=$ number of peeps into open beams; $2=$ number of entries into closed beams; $3=$ total number of transition; 4 = freezing time. Control: $n=30$; study group: $n=30$.

Statistical significance (Wilcoxon-Mann-Whitney $U$-criteria): ${ }^{*} p<.05 .{ }^{* *} p<.01 . * * * p<.005$.
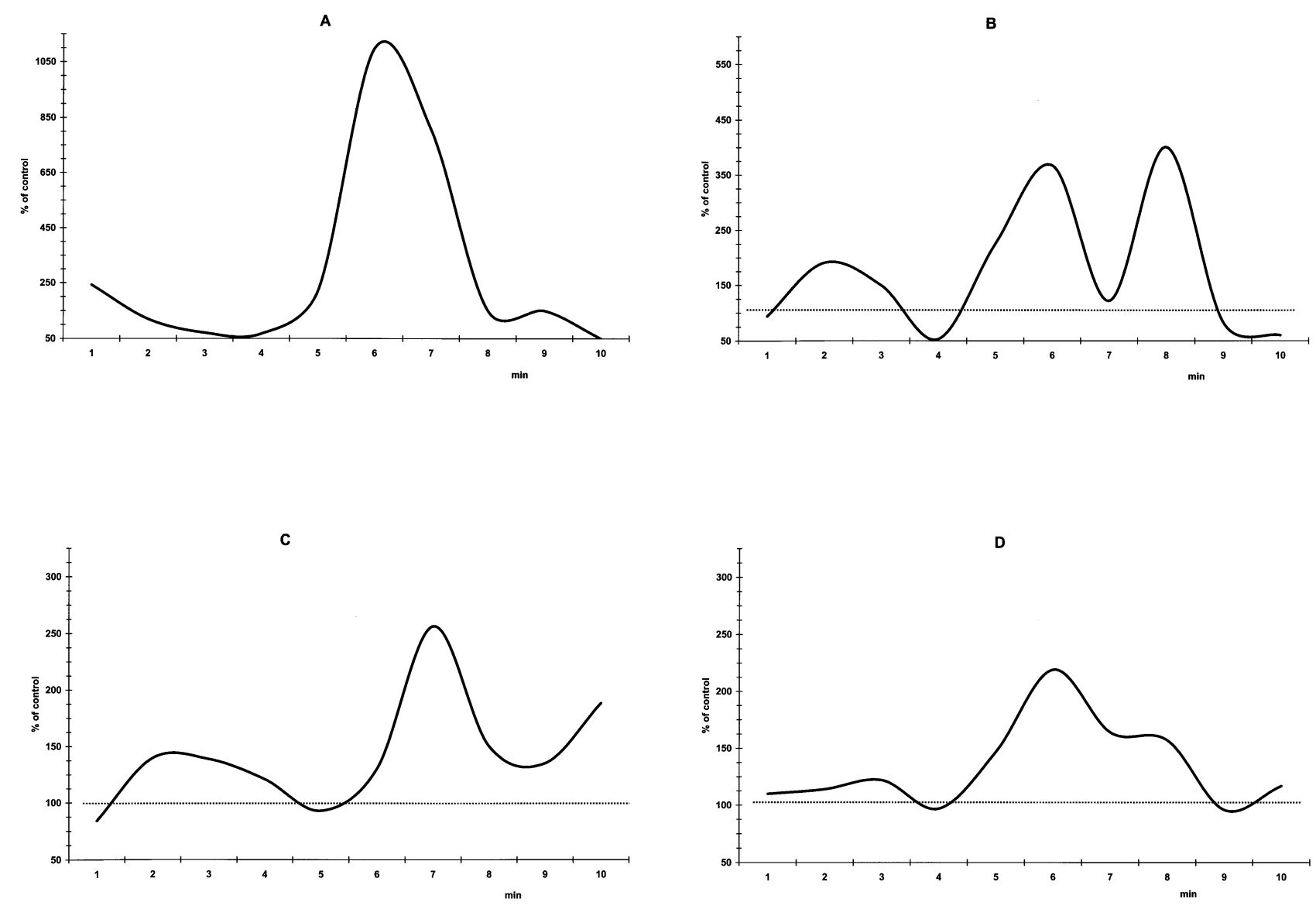

Figure 5. Changes in motor and orientation-exploratory activity in rats immunized with CCK-4 BSA conjugate (\% of control group). $\mathrm{A}=$ number of peeps into upper burrows; $\mathrm{C}=$ number of stances; $\mathrm{B}=$ number of peeps into lower burrows; $\mathrm{D}=$ horizontal activity. Control: $n=10$. 


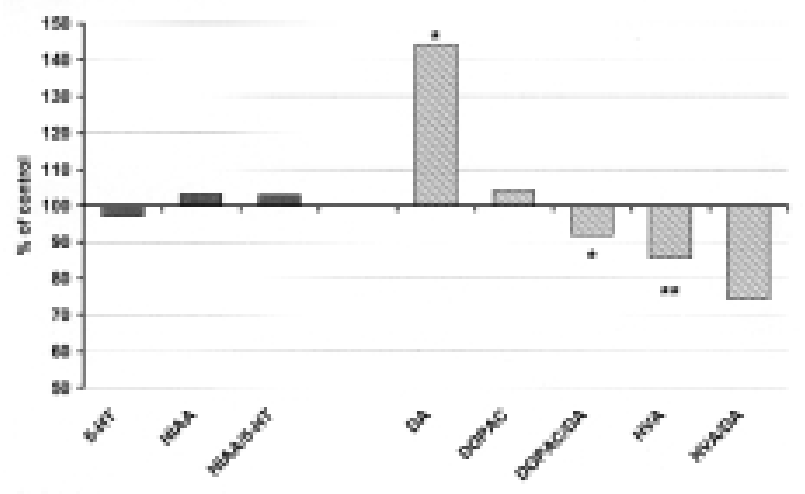

Figure 6. Biochemical changes in rat brain striatum following immunization with CCK-4 BSA conjugate (\% of control).

Control group: $n=12$; study group: $n=12$.

Statistical significance (Wilcoxon-Mann-Whitney $U$-criteria): *p $<.05 . * * p<.01$.

Thus, immunization with CCK-4 (and CCK-3) rendered an anxiolytic and antidepressive effect. It should be noted that the anxiolytic effect was observed not only in the usual selection of rats, but also in the rats selected with an initially high level of anxiety. Prior to immunization, a large group of rats was tested in the cruciform maze, according to the results of which rats with a high level of initial anxiety were chosen, and then used for immunization. The acquired data reveals the importance of the use of such an approach for the correction of the pathological manifestations of anxiety.

Immunological and biochemical effects. Immunological assessments of blood plasma of immunized rats showed a slight, but statistically significant, concentration of antibodies to CCK-4 (1/3200-1/6400). Biochemical analysis of the brain striatum of rats immunized with $\mathrm{CCK}-4$ and BSA conjugate revealed several changes in the concentration of biogenic amines. As shown in Figure 6, there was a statistically significant increase in DA concentration, and decreases in DA metabolite HVA and HVA/DA and DOPAK/DA ratios. The concentration of 5-HT remained unaltered. The biochemical changes after CCK-4 immunization as well as behavioral changes are opposite to those resulting form MAO inhibitor immunization.

\section{Discussion}

The present study shows that the induction of autoantibodies following the active immunization of rats with endogenous (isatin) and some exogenous (pargyline, deprenyl) monoamine oxidase inhibitors leads to a depressed state with elements of anxiety in experimental animals. The duration of depression symptoms in the animals exceeds 2 months.

The modeling of depression in white rats using isatin immunization is prospective as, firstly, a compound identical to the endogenous regulator is used; secondly, the effect is achieved with minimal intervention; and thirdly, a long duration of model effect is achieved. At the same time, not only the similarity to anxiety depression in man is achieved, but also a great correspondence to contemporary theories of the mechanisms of depression. In combination with the duration of effect, all these facts determine the advantages of the suggested model over other methods described.

In relation to the effectiveness of the model in terms of trials of known antidepressants, the above described effect of fluoxetine is the first positive demonstration of its kind, although the expediency of the widespread approbation of other antidepressants is obvious.

At the same time, various studies have shown that psychiatric patients show significant levels of antibodies to several brain antigens and haptens. The induction of antibodies to serotonin and dopamine in rats with an experimental dopamine-deficit-related depression syndrome has been demonstrated (Kryzhanovsky, Man'kovsky, Karaban', et al., 1994). It is probable that one of the leading causes of protracted depressive states may be an autoimmune process, and specifically, the formation of auto-antibodies to the endogenous MAO inhibitor isatin or isatin containing tribuline. The protracted circulation of such antibodies leads to an annihilation of the inhibitory effect of isatin on MAO and the increased decomposition of serotonin and dopamine. The penetration of antibodies through the hematoencephalic barrier under conditions of protracted circulation of these antibodies has been demonstrated (Burlet, Leon-Henri, Robert, Arachmani, et al., 1987; Banks \& Kastin, 1987, 1988, 1990; Meeker, Meeker, \& Hayward, 1987; Poduslo, Curran, \& Berg, 1994; Relber, Kitze, Link, \& Wagner, 1988).

A decrease in the concentration of serotonin and dopamine is a well known factor for the development of depression. Confirmation of this are the biochemical changes in the brain revealed in this study. It is possible that the level of isatin antibodies may be used to assess the severity of depression and/or latent depression.

On the other hand, induction of protracted depression by immunization with MAO inhibitors pargyline, deprenyl and in particular, isatin, is of interest for the treatment of maniacal and aggressive states.

The immunization with conjugated CCK-4 (peptides inducing fear, panic states, and depressive behavior in animals and, in particular, man) that we have demonstrated, accompanied by the formation of antibodies to CCK- 4 and caused effects opposite to those of CCK-4. It allows the positive assessment of the prospects of the present direction for immuno-correction of depression and anxiety.

The immunological approach to long-term correction of some pathophysiological states is already in practice (Stevens, 1996) or is at the stage of preclinical trials (Kosten, Rosen, Bond, Settles, Roberts, et al., 2002). However, while assessing the possibilities of the present approach for practical correction of depression and anxiety, it is important to consider the very high complexity of these diseases. 


\section{References}

Arushanyan, E.B., \& Bayer, E.B. (2004). Interaktivnoe psychoemotsional'noe sostoyanie I aktivnost' immunoi sistemy [Interactive psycho-emotional states and activity of the immune system], Uspehi Fiziiologiceskih nauk, 35, 49-64.

Ashmarin, I.P., Danilova, R.A., Mashkovskii, M.D., Mel'nic, E.I., Obukhova, M.F., Sagimbaeva, Sh.K., \& Zirenina, M.L. (1990). Active immunization against bioregulators: Behavioral and catecholamine changes in albino rats immunized against sydnophen. Biomedical Science, 1, 95-98.

Ashmarin, I.P., Danilova, R.A., Mel'nik, E.I., Obukhova M.F., Sagimbaeva Sh.K., Zirenina M.L., \& Ganzha, S.V. (1989). Immunologicheskoe vmeshatel'stvo v neirokhimicheskie i neiropsikhologicheskie protsessy : katekholaminy, pevedenie i sudorozhnaya gotovnost' belykh krys, immunizirovanykh kon'ugatom seroal'buminom s sidofenom [Immunologic intervention in neurochemical and neurophysiologic processes : Catecholamines, behaviour, and convulsion readiness in white rats immunized with seroalbumin sydnophen conjugate]. Neirokhimia, 8, 328-335.

Ashmarin, I.P., Danilova, R.A., \& Obukhova, M.F. (2001). Dlitel'naya korrektsia funktsii mozga, perspektivy immunologicheskikh podkhodov [Protracted correction of brain functions, prospects of immunologic approaches]. Vestnik RAMN, 4, 27-30.

Ashmarin, I.P., Danilova, R.A., Rud'ko, O.I., Obukhova, M.F., \& Andreeva, L.A. (2004). Dolgovremennje deistvie peptidnykh regulyatorov, otlozhennye i inversnye effekty kholetsistokinina - 4 i 3. [Long-term action of peptide regulators, delayed and inverse effects of cholecystokinine - 4 and 3]. Medizinskii akademicheskii Zhurnal, 4, 4-13.

Ashmarin, I.P., \& Gomazkov, O.A. (1992). Active immunization against neurotransmitters and neuromodulators as a means of long-term correction of physiological function. Sov. Sci. Rev. F. Physiol. Gen. Biol, 5, 1-37.

Banks, W.A., \& Kastin, A.J. (1987). Saturable transport of peptides across the blood-brain barrier. Life Science, 41, 1319-1338.

Banks, W.A., \& Kastin, A.J. (1988). Interactions between the bloodbrain barrier and endogenous peptides: emerging clinical implications. American Journal of Medical Science, 295, 459471.

Banks, W.A., \& Kastin, A.J. (1990). Peptide transport systems for opiates across the blood-brain barrier. American Journal of Physiology, 259, 1-10.

Burlet, A.J., Leon-Henri, B.P., Robert, F.R., Arachmani, A., Femette, B.M., \& Burlet, C.K. (1987). Monoclonal anti-vasopressin (VP) antibodies penetrate into VP neurons, in vivo. Experimental Brain Research, 65, 629-638.

Danilova, R.A., \& Ashmarin, I.P. (1994). Inversnaya immunoregulyatsia povedenia I problema suschestvovania regulyatornykh antitel [Inverse immunoregulation and the problem of the existence of regulatory antibodies]. Uspehi Fiziiologiceskih nauk, 25, 3-23.

Danilova, R.A., Belopolskaya, M.V., Kushnir, E.A., Moskvitina,
T.A., Afanasjev, I.I., Andiarzhanova, E.A., Obukhova, M.F., Shevchenko, V.P., \& Ashmarin, I.P. (2000). Dolgovrmennoe izmenenie biokhumicheskogo i fiziologicheskogo statusa belykh krys immunomodulyatsiei aktivnosti monoaminooksidazy [Long-term changes in biochemical and physiologic states of white rats with immunomodulation of the activity of monoaminooxidase]. Neirokhimia, 17, 192-197.

Danilova, R.A., \& Fedorova, I.M. (2001).The effects of immunization against cholecystokinin (30-33) on rats behavior. Federation of American Societies for Experimental Biology, 15, 913.

Danilova, R.A., Moskvitina, T.A., Obukhova, M.F., Belopolskaya, M.V., \& Ashmarin, I.P. (1999). Pargyline conjugate-induced long-term activation of monoamine oxidase as an immunological model for depression. Neurochemical Research, 24, 1149-1153.

Danilova, R.A., Obukhova, M.F., Ashmarin, I.P., \& Mashkovskii, M.D. (1988) .Dlitel'noe izmenenie emotsional'nogo stausa i obuchaemosti belykh krys posle immunizatii kon'ugatom sidnofenom s serual'buminom [Protracted alterations in emotional state and learning of white rats following immunization with sydnophen seroalbumin conjugates]. Dokladi AN SSS, 303, 1512-1514.

Danilova, R.A., Obukhova, M.F., Belopolskaya, M.V., \& Ashmarin, I.P. (1998). Induktsia dlitel'nogo sostoyaniya depressii (s komponentami trevozhnosti I strakha) immunizirovanykh krys $\mathrm{k}$ pargilinu [Induction of protracted depression states (with anxiety and fear components) in rats immunized with pargyline]. Vestnik RAMN, 8, 27-32.

Danilova, R.A., Rud'ko, O.I., Korotkova, T.M., Obukhova, M.F., \& Ashmarin, I.P. (2002). The effects of immunization against cholecystokinin fragment 30-33 in the behavior of white rats. Neuroscience and Behavioral Physiology, 32, 189-194.

Friedman, E.M., Becker, K.A., Overstreet, D.H., \& Lawrence, D.A. (2002). Reduced primary antibody responses in a genetic animal model of depression. Psychosomatic Medicine, 64, 267273.

Kosten, T.R., Rosen, M., Bond, J., Settles, M., Roberts, J.S., Shields, J., \& Jack, L. (2002). Human therapeutic cocaine vaccine: Safety and immunogenecity. Vaccine, 20, 1196-1204.

Kryzhanovsky, G.N., Man'kovsky, N.B., Karaban', I.N., \& Evseev, V.A (1994). Antitela k serotoninu I ikh vozmozhnaya rol' pri parkinsonizme [Serotonine antibodies and their probable role in Parkinsonism]. Zhurnal Nevropatalogii I psykhiatrii, 94, 2125.

Leonard, B.E. (2001). The immune system, depression and the action of antidepressants. Progress inNeuro-psychopharmacology and Biological Psychiatry, 25, 767-780.

Medvedev, A.E., \& Glover, V. (2004). Tribulin and endogenous MAO-inhibitory regulation in vivo. NeuroToxicology, 25, 185192.

Meeker, M.L., Meeker, R.B., \& Hayward, J.N. (1987). Accumulation of circulating endogenous and exogenous immunoglobulins by hypothalamic magnocellular neurons. Brain Research, 423, 45-55. 
Poduslo, J.F., Curran, Q.L., \& Berg, C.T. (1994). Macromolecular permeability across the blood-nerve and blood-brain barriers. Proceedings of the National Academy of Sciences of the United States of America, 91, 5705-5709.

Relber, H., Kitze, B., Link, M., \& Wagner, R. (1988). Cellular immune reactions and blood cerebrosplnal fluid barrier dysfunction in guinea pigs. Neurochem.Res., 13, 463-466.
Stevens, V.S. (1996). Progress in the development of human chorionic gonadotropin antifertility vaccines. American Journal of Reproductive Immunology and Microbiology, 35, 148-155.

Received April 24, 2006 Review received May 16, 2006 Accepted July 11, 2006 